\title{
Level of physical activity among urban adults and the socio-demographic correlates: a population-based cross-sectional study using the global physical activity questionnaire
}

Melkamu Merid Mengesha ${ }^{1 *}$ (D), Hirbo Shore Roba ${ }^{1}$ (D), Behailu Hawulte Ayele ${ }^{2}$ (D) and Addisu Shunu Beyene $e^{3,4}$

\begin{abstract}
Background: Globally, in 2016, 23.3\% of adult populations were physically inactive, and it accounts for 9\% of the global premature mortality. However, evidence on the level of physical activity was limited in resource-poor settings. This study, therefore, assessed the adult's level of physical activity and its correlates among the urban population in Dire Dawa, eastern Ethiopia.

Methods: A total of 872 randomly selected adults of age 25-64 years in Dire Dawa city, eastern Ethiopia, are included in this analysis. The Global Physical Activity Questionnaire (GPAQ) is used to measure physical activity. Individuals are considered physically active when they achieved metabolic equivalent tasks (MET) minutes of 600 or more per week, and otherwise inactive. A binary logistic regression is used to identify the correlates of physical activity.

Results: $54.9 \%$ ( $95 \%$ confidence interval (Cl) 51.6 to 58.2) of adults were physically active, with a higher proportion of men being physically active than women, $63.9 \%$ ( $95 \% \mathrm{Cl} 58.1$ to 69.3 ) versus $50.6 \%$ ( $95 \% \mathrm{Cl} 46.5$ to 54.6 ). Among the adults who reported doing physical activity, the highest domain-specific contribution to the total physical activity was from activities at workplaces, and leisure-time activities contributed the least. The proportion of adults who engaged in a high-level physical activity was $37.0 \%$ (95\% Cl 33.9 to 40.3). Male adults were 1.45 times (aOR (adjusted odds ratio) $=1.45 ; 95 \% \mathrm{Cl} 1.05$ to 1.99 ) more likely to achieve the recommended level of physical activity. In contrary, unemployed adults ( $\mathrm{aOR}=0.51 ; 95 \% \mathrm{Cl} 0.35$ to 0.75 ) were less likely to perform the recommended level of physical activity to accrue health benefits.
\end{abstract}

Conclusion: Interventions aimed at promoting physical activity should target unemployed and female adults. We recommend further study to explore the contextual factors that hinder physical activity in the study setting.

Keywords: GPAQ, Level of physical activity, Correlates, Adult, Dire Dawa

\footnotetext{
* Correspondence: survivalepi@gmail.com

${ }^{1}$ Department of Epidemiology and Biostatistics, College of Health and

Medical Sciences, School of Public Health, Haramaya University, P.O. Box 235,

Harar, Ethiopia

Full list of author information is available at the end of the article
}

(c) The Author(s). 2019 Open Access This article is distributed under the terms of the Creative Commons Attribution 4.0 International License (http://creativecommons.org/licenses/by/4.0/), which permits unrestricted use, distribution, and reproduction in any medium, provided you give appropriate credit to the original author(s) and the source, provide a link to the Creative Commons license, and indicate if changes were made. The Creative Commons Public Domain Dedication waiver (http://creativecommons.org/publicdomain/zero/1.0/) applies to the data made available in this article, unless otherwise stated. 


\section{Background}

Insufficient physical activity is the fourth leading cause of death worldwide [1]. The World Health Organization (WHO) defines the level of physical activity less than 600 metabolic equivalent tasks (MET) minutes per week as not sufficient to produce health benefits [2]. Physical inactivity is causally associated with coronary heart diseases, breast cancer, and colon cancer [3]. Additionally, it accounts for $9 \%$ of the global premature mortality [3]. In terms of the burden on the economy, deaths due to physical inactivity contribute to $\$ 13.7$ billion in productivity losses. Additionally, regarding its impact on an individual's quality of life, physical inactivity accounts for 13.4 million disability-adjusted life years (DALYs) worldwide [4].

Globally, in 2016, the prevalence of physical inactivity among adult populations was 23.3\% [5]. A review by Guthold R et al. in 22 African countries reported that $20 \%$ of adults were physically inactive [6]. In Ethiopia, the WHO STEPwise approach to Surveillance (STEPS) survey report for Addis Ababa showed a slight increase in the proportion of physically inactive adults between 2006, and 2015, 26\% versus $28.8 \%$ [7, 8].

Physical inactivity is a modifiable risk factor for NCD, and being physically active has several benefits for health. The population attributable fraction (PAF) of physical inactivity for coronary heart disease, type 2 diabetes, breast cancer, colon cancer, and all-cause mortality was $5.8,7.2,10.1,10.4$, and $9.4 \%$, respectively [3]. A study by Huerta et al. reported that physical activity at workplaces and household chores were strongly associated with a reduced overall and cause-specific mortality in women and to lower cancer mortality in men [9]. There are also strong pieces of evidence that physical activity increases cardiorespiratory and muscular fitness, healthier body mass and composition, improved bone health, increased functional health, and improved cognitive function [3, 5]. A meta-analysis, on the dose-response relationship of physical activity and mortality, reported that higher levels of total and domain-specific physical activities reduce all-cause mortality [10]. Despite that physical activity has several benefits, the population around the world continue to suffer from the pandemic of physical inactivity $[1,3,9]$. Attempts to respond to this pandemic has led countries including physical activity in their national policies, even though, this response is too slow and ineffective [5].

Research evidence reported correlates of physical activity at the individual, interpersonal, and environmental levels [11-13]. For instance, Bauman et al. reported that male gender, level of education, self-efficacy, and social support were positive correlates of physical activity. Whereas, age, overweight, and perceived effort are inversely correlated [11]. The environmental correlates of total physical activity among adults include access to recreation facilities and locations, transportation environment, and aesthetics [11, 14, 15]. A study examining physical inactivity in India reported that there was no statistically significant difference in the proportion of the physically inactive population, based on gender, or age groups [16]. Despite several studies are conducted in high-income or upper-middle-income countries, on the correlates of physical activity, there was limited evidence in low-income countries to guide locally appropriate interventions [11].

In Ethiopia, the STEPS surveys conducted in 2006 in Addis Ababa, and at the national level in 2015, did not report the correlates of physical activity $[7,8]$. Therefore, this study aimed to assess the level of physical activity and its correlates among the urban population in Dire Dawa, eastern Ethiopia. In this study, we collected data from a large representative sample compared to the subnational sample for Dire Dawa in the national STEPS survey [7].

\section{Methods \\ Study setting and design}

A population-based cross-sectional study was conducted from June $01 / 2017$ to June $21 / 2017$ in Dire Dawa city, eastern Ethiopia. The city has 4 Keftegnas (districts) and 9 urban kebeles (sub-district, the lowest administrative unit). Located at $515 \mathrm{~km}$ to the southeast of Addis Ababa, Dire Dawa city is the capital of the Dire Dawa Administrative Council (DDAC) which has an estimated urban population of 252, 279 [17]. Dire Dawa lies between 1000, and $2000 \mathrm{~m}$ above the sea level. It has an average monthly temperature of 24.8 degree Celsius and an average annual rainfall of $604 \mathrm{~mm}$ [18].

\section{Participants}

Adults aged 25-64 years, who lived in Dire Dawa city for at least six months before the survey, are included in this study. In each household, an adult resident was identified, and only one was randomly selected to participate in the study when there was more than one adult in that household. Excluded from the study were pregnant women, bedridden adults, and those who had a disability that limits activity.

\section{Sample size}

This study used the sample calculated for a study on metabolic syndrome (unpublished) in the study setting. A single population proportion formula was used to calculate the sample size for the original study. The sample size is calculated using the OpenEpi v 2.3 software [19]. The assumptions used to calculate the sample size were the prevalence of metabolic syndrome, $P=17 \%$ [20]; margin of error, $d=3 \%$; a design effect of 1.5 to 
compensate for a random error due to a multi-stage sampling, and 95\% level of confidence. Accordingly, the minimum calculated sample size was 903 . Of the total 903 samples, 872 subjects who completed the survey were available for this analysis.

\section{Sampling technique}

Multi-stage sampling was used to select the sub-districts, primary sampling units (households), and the study units (adults, 25-64 years). From the 9 urban sub-districts in the study setting, five were randomly selected. A sampling frame was created using a list of households obtained from the Dire Dawa city sub-district administration. The study sample was then proportionally allocated to each of the selected sub-districts based on their size. Systematic random sampling was used to select the primary sampling units. When there was more than one eligible adult in a selected household, one was randomly selected.

\section{Data collection}

The WHO STEPS instrument was used to collect the data [21]. The English version of the STEPS instrument was translated into the two widely spoken local languages in the study setting, Amharic and Afan Oromo, and then, it was back-translated to English to check the consistency. When inconsistency occurred, based on consensus, corrections are made as appropriate. Before the actual data collection, a pretest of the instrument was conducted using the local translated version. For this analysis, we considered variables on demographic information, behavioral measurements (physical activity), and physical measurements (height and weight). Weight is measured using a standard portable digital scale. Stadiometer was used to measure height, and the results are recorded to the nearest $0.5 \mathrm{~cm}$. Demographic information collected includes age, sex, education, ethnicity, marital status, and occupation. The occupation variable assessed participant's main work status over the past 12 months. Adults participated in this study are said to be unemployed if she or he was not in employment, not engaged in any activity to produce goods or services for pay or profit during the 7 days before the survey, or in the 12 months before the survey. Research assistants who completed at least diploma level of education and had a health background collected the data and the data collection activity were supervised daily. Three days orientation was given to research data assistants on the study protocol including its objective, data collection methods, STEPS survey procedure, and also on data quality.

\section{Definitions and measurements}

The global physical activity questionnaire version-2 (GPAQ-2) was used to measure physical activity [22]. It has a total of 16 questions (P1-P16) that assess sedentary behavior and three domains in which physical activity is performed: work, transport, and leisure-time physical activity. Study participants were asked if they had engaged in vigorous and moderate work and leisure-time activities continuously for at least $10 \mathrm{~min}$. Transport related activities include only moderate-intensity activities worked out continuously for at least $10 \mathrm{~min}$. Participants responding affirmatively of their engagement in a specific activity were asked about the number of days engaging in each activity in a typical week, and the time spent in each activity in a typical day. The responses to the frequency and duration questions are used to calculate the total amount of time a person spent doing physical activity or MET minutes per week. Vigorousintensity activity is defined as an activity that makes an individual breathe much harder than normal, and a moderate-intensity activity makes an individual breathe somewhat harder than normal. We used the generic GPAQ show cards to aid in obtaining consistent and valid measurements [22]. In the GPAQ, sedentary behavior was assessed through the question "How much time do you usually spend sitting or reclining on a typical day?"(Additional file 1: Table S1).

For adults aged 18-64 years, the WHO global recommendation on physical activity for health is to do at least 150 min of moderate-intensity physical activity throughout the week; or $75 \mathrm{~min}$ of vigorous-intensity physical activity throughout the week; or an equivalent combination of moderate- and vigorous-intensity activity accumulating at least 600 MET-minutes per week [22]. In our study, we used this cut-off to define physically active (achieved 600 or more MET-minutes per week) versus inactive adults (achieving less than 600 MET-minutes per week).

We also characterized adult's physical activity using cut-offs into high (achieving a minimum of at least 3000 MET-minutes per week from any combination of walking, moderate-or vigorous-intensity activities or accumulating 1500 MET-minutes per week from vigorousintensity activity), moderate (a person not meeting the criteria for the high category, but achieved a minimum of at least 600 MET-minutes per week from any combination of walking, moderate-or vigorous-intensity activities) and low (a person not meeting any of the above criteria. This included those reporting no activity or some, but not enough to meet the high and moderate categories) [23].

\section{Data processing and analysis}

The data were entered into EpiData version 3.0 and then exported to STATA version 14.2 statistical software for management and analysis. We followed the GPAQ-2 data processing and analysis protocol, where all the three domains of physical activity are cleaned as a combined 
set, to produce estimates on physical activity [22]. Issues of missing values were handled using multiple imputations by chained equations (MICE) method [24] for five variables which accounted for $11.5 \%$ of missing values if a complete case analysis would have been considered. The variables imputed include ethnicity (48 values), years in school (33 values), height (27 values), weight (13 values) and age (12 values). Before imputation, we checked the pattern of missing, and the Little's missing completely at random (MCAR) test in STATA supported that all the variables were MCAR (chi-square $(\mathrm{df})=159.55(172), p$-value $=0.743)$.

In each of the three domains of physical activity in the GPAQ, responses to questions on the frequency and duration of physical activity are used to convert the total time spent on activity to energy expenditure, the METminutes [22]. A MET is the ratio of specific physical activity metabolic rates to the resting metabolic rate, with one MET defined as the energy cost of sitting quietly which is equivalent to $1 \mathrm{kcal} / \mathrm{kg} /$ hour [23]. Compared to the energy expenditure when seated quietly, a person's caloric consumption is four times higher when being moderately active, and eight times higher when being vigorously active. Accordingly, moderate-intensity activities during work, transport, and leisure-time are assigned a value of $4 \mathrm{MET}$; and vigorous-intensity activities are assigned a value of 8 METs. Hence, to convert a vigorous-intensity activity for 75 -min in a week into MET-minutes, multiply 75 -min by 8 -METs, which equals 600 MET-minutes per week. Consequently, the total physical activity score is computed as the sum of all MET-minutes per week from moderate- to vigorousintensity activities performed at workplaces, during transport, and leisure-time [22]. The total physical activity of $\geq 600$ MET-minutes per week denotes adequate physical activity or being physically active, and an inadequate level of physical activity or physical inactivity was represented by < 600 MET-minutes per week. Adequate physical activity was coded ' 1 ' and an inadequate level of physical activity was coded ' 0 '. The results are summarized in tables, graphs and also presented in text. We used the two-sample Wilcoxon rank-sum (Mann-Whitney) test to see the relationship between two variables, and the binary logistic regression to identify correlates of physical activity. For all statistical tests, significance was defined as $p$-value $<0.05$.

\section{Ethical clearance}

Ethical clearance was obtained from the Haramaya University College of Health and Medical Sciences' Institutional Health Research Ethics Review Committee (IHRERC), with an approval number, IHRERC/003/ 2016. Additionally, to conduct the field activity in Dire Dawa, a letter of permission was obtained from the
DDAC. Informed written consent was sought beforehand to obtain data from each of the participants. Confidentiality of the information collected is maintained by keeping the anonymity of individual participants at all levels.

\section{Results}

\section{Socio-demographic characteristics}

A total of 872 subjects participated in this study, and more than half $(67.2 \%)$ of them were females. The majority, $64 \%$ of the study participants, were below the age of 45 years with a mean age of 40.4 years. Fifty-two percent of the respondents either completed primary education or had no formal education. Unemployed participants constituted $45.0 \%$ of the sample, while $27.0 \%$ were office work employees. Currently married adults constituted $67.0 \%$ of the sample (Table 1 ).

\section{Self-reported physical activity by specific domains}

Of the total study participants, $34.1 \%$ reported no physical activity that lasted for at least 10 -min continuously in any of the three physical activity domains. Whereas, out of the $65.9 \%$ who reported doing physical activity for

Table 1 Socio-demographic characteristics of adults (25-64 years) in Dire Dawa city, eastern Ethiopia, 2017

\begin{tabular}{|c|c|c|c|}
\hline Variables & & $\begin{array}{l}\text { Frequency, } \\
n=872\end{array}$ & Percent (\%) \\
\hline Age, mean (SD) & $40.4(13.0)$ & & \\
\hline \multirow[t]{4}{*}{ Age } & $25-29$ & 231 & 26.5 \\
\hline & $30-44$ & 326 & 37.4 \\
\hline & $45-54$ & 124 & 14.2 \\
\hline & $55-64$ & 191 & 21.9 \\
\hline \multirow[t]{2}{*}{ Sex } & Male & 285 & 32.7 \\
\hline & Female & 587 & 67.3 \\
\hline \multirow[t]{4}{*}{ Education } & No formal education & 125 & 14.3 \\
\hline & Primary (1-8 grade) & 327 & 37.5 \\
\hline & Secondary (9-12 grade) & 316 & 36.2 \\
\hline & College diploma and above & 104 & 11.9 \\
\hline \multirow[t]{3}{*}{ Marital status } & Currently married & 582 & 66.7 \\
\hline & Never married & 173 & 19.8 \\
\hline & Divorced/Widower & 117 & 13.4 \\
\hline \multirow[t]{3}{*}{ Ethnicity } & Oromo & 302 & 34.6 \\
\hline & Amhara & 428 & 49.1 \\
\hline & Others $^{a}$ & 142 & 16.3 \\
\hline \multirow[t]{4}{*}{ Occupation } & Employed office work & 234 & 26.8 \\
\hline & Merchant & 134 & 15.4 \\
\hline & Unemployed & 396 & 45.4 \\
\hline & Others§ & 108 & 12.4 \\
\hline
\end{tabular}

aEthio-Somali, Harari, Tigraway, Guraghe, Wolayta, Silte, Afar; §housewife, pensioner, janitor, and daily laborer; $S D=$ standard deviation 
at least 10-min continuously, 59.0\% reported moderate-intensity physical activity at workplaces and $53.9 \%$ reported activity during travel to and from places. These are the common physical activity in the study setting. Vigorousand moderate-intensity leisure-time activities were the least commonly practiced among adults (Fig. 1).

Compared to the other physical activity domains, activities at the workplaces had the highest median percent contribution to the total physical activity, $93.0 \%$, with no statistically significant difference between males and females. In contrast, the median percent contribution of activities during leisure-time to the total physical activity was null in the study setting (Table 2).

Approximately 22\% (95\% CI 18.4 to 25.1 ) of the adults did vigorous-intensity activity for 75 -min or more per week. The proportion of men who did vigorous-intensity activity were more than three-fold higher compared to women, $39.3 \%$ (95\% CI 32.7 to 46.3 ) versus $12.0 \%$ (95\% CI 9.1 to 15.8), and the difference was statistically significant. Similarly, a significantly higher proportion of men were engaged in either a moderate-intensity activity or a vigorous-intensity activity. Of the adults who reported doing physical activity, $16.2 \%$ (95\% CI 13.4 to 19.4) did both vigorous and moderate-intensity activity, and this too was significantly higher among men. The proportion of adults who did high-level physical activity was $37.0 \%$ (95\% CI 33.9 to 40.3). Regarding sedentary activities, women had significantly higher median time spent in sitting compared to men, 300 min per week versus 240 min per week (Table 2).

\section{Physical activity level in the study setting against the WHO recommendation}

The proportion of physically active adults in this study was $54.9 \%$ (95\% CI 51.6 to 58.2), with a higher proportion of men being physically active than women, $63.9 \%$ (95\% CI 58.1 to 69.3 ) versus $50.6 \%$ (95\% CI 46.5 to 54.6 ) (Fig. 2).

When the participant's level of physical activity was disaggregated by the WHO global recommendation on physical activity for health, females who achieved the recommended level were over $10 \%$ lower than those who did not, $62.0 \%$ versus $73.8 \%$. Similarly, $39.5 \%$ of unemployed adults achieved the recommended level, and

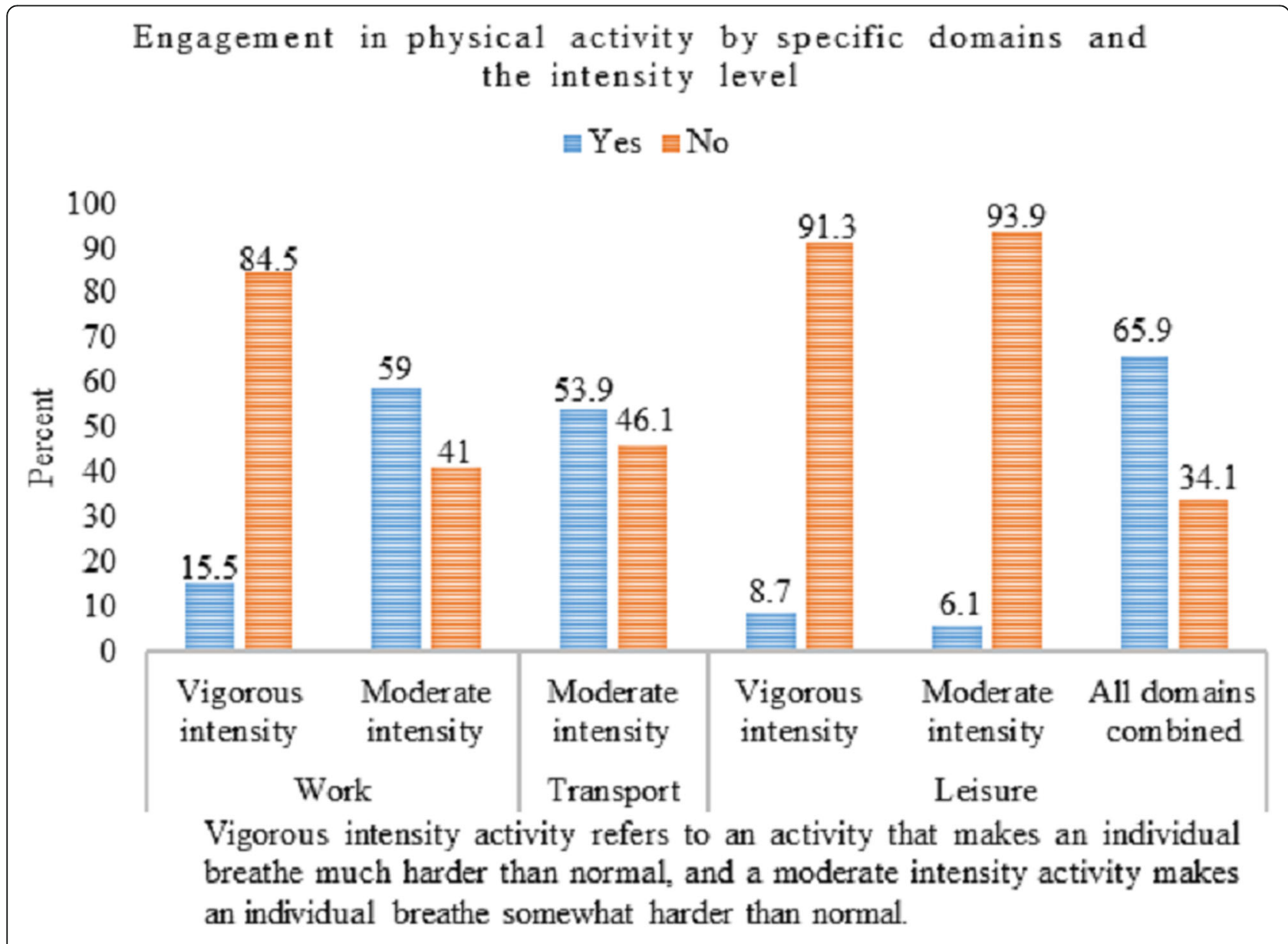

Fig. 1 Proportion of adults (25-64 years) who engage in physical activity by specific domains and intensity level in Dire Dawa city, eastern Ethiopia, 2017 
Table 2 Self-reported physical activity in a typical week among adults (25-64 years) in Dire Dawa city, eastern Ethiopia, 2017

\begin{tabular}{|c|c|c|c|c|c|}
\hline Physical activity measures & $\begin{array}{l}\text { Both sexes, } n=872 \text {; } \\
(95 \% \mathrm{Cl})\end{array}$ & $\begin{array}{l}\text { Male, } n=285 \\
95 \% \mathrm{Cl}\end{array}$ & $\begin{array}{l}\text { Female, } n=587 \\
95 \% \mathrm{Cl}\end{array}$ & $\begin{array}{l}\text { Pearson's } \\
\text { Chi2 (df) }\end{array}$ & $P$-value \\
\hline Total MET minutes per week, median (IQR) & $5040(672,11,520)$ & $10,080(1680,14,400)$ & $2580(672,10,080)$ & $Z=5.8$ & $<0.001^{c}$ \\
\hline \multicolumn{6}{|c|}{ Domain specific median percent contribution to the total physical activity } \\
\hline Work (median \% (IQR)) $)^{d}$ & $93.0(0,100)$ & $90.3(0,100)$ & $95.4(0,100)$ & $Z=0.4$ & $0.659^{c}$ \\
\hline Transport (median \% (IQR) $)^{d}$ & $2.2(0,100)$ & $1.6(0,26.9)$ & $4.1(0,100)$ & $Z=-2.8$ & $0.004^{c}$ \\
\hline Leisure (median \% (IQR)) ${ }^{d}$ & 0.0 & $0.0(0,3.4)$ & 0.0 & $Z=8.7$ & $<0.001^{\mathrm{c}}$ \\
\hline \multicolumn{6}{|c|}{ The proportion of participants within a specific level of intensity of physical activity } \\
\hline Vigorous physical activity, $\geq 75 \mathrm{~min} /$ week $^{\mathrm{d}}$ & $21.6(18.4,25.1)$ & $39.3(32.7,46.3)$ & $12.0(9.1,15.8)$ & $57.5(1)$ & $<0.001$ \\
\hline Moderate physical activity, $\geq 150 \mathrm{~min} /$ week $^{\mathrm{d}}$ & $77.9(74.3,81.1)$ & $83.1(77.2,87.7)$ & $75.1(70.4,79.3)$ & $4.8(1)$ & 0.028 \\
\hline Both moderate and vigorous physical activity ${ }^{d}$ & $16.2(13.4,19.4)$ & $31.8(25.7,38.7)$ & $7.8(5.4,11.0)$ & $55.9(1)$ & $<0.001$ \\
\hline \multicolumn{6}{|c|}{ The proportion of participants within a level physical activity category ${ }^{b}$} \\
\hline High & $37.0(33.9,40.3)$ & $47.4(41.6,53.2)$ & $32.0(28.4,35.9)$ & $20.1(1)$ & $<0.001$ \\
\hline Moderate & $17.9(15.5,20.6)$ & $16.5(12.6,21.3)$ & $18.6(15.6,21.9)$ & & \\
\hline Low & $45.1(41.8,48.4)$ & $36.1(30.7,41.9)$ & $49.4(45.4,53.5)$ & & \\
\hline Median time (IQR) spent sitting ${ }^{\mathrm{a}}$ & $300(180,480)$ & $240(120,420)$ & $300(240,480)$ & $Z=-3.7$ & $<0.001^{c}$ \\
\hline
\end{tabular}

${ }^{a}$ Duration measured in minutes

blow: < 600 MET-minutes per week; moderate: 600 to < 3000 MET-minutes per week, and high: $\geq 3000$ MET-minutes per week

${ }^{c}$ Two-sample Wilcoxon rank-sum (Mann-Whitney) test; $I Q R=$ Inter quartile range, $C l$ confidence interval

${ }^{d}$ computation did not include those who reported no activity $(N=297$ : Male $=84$, Female $=213)$

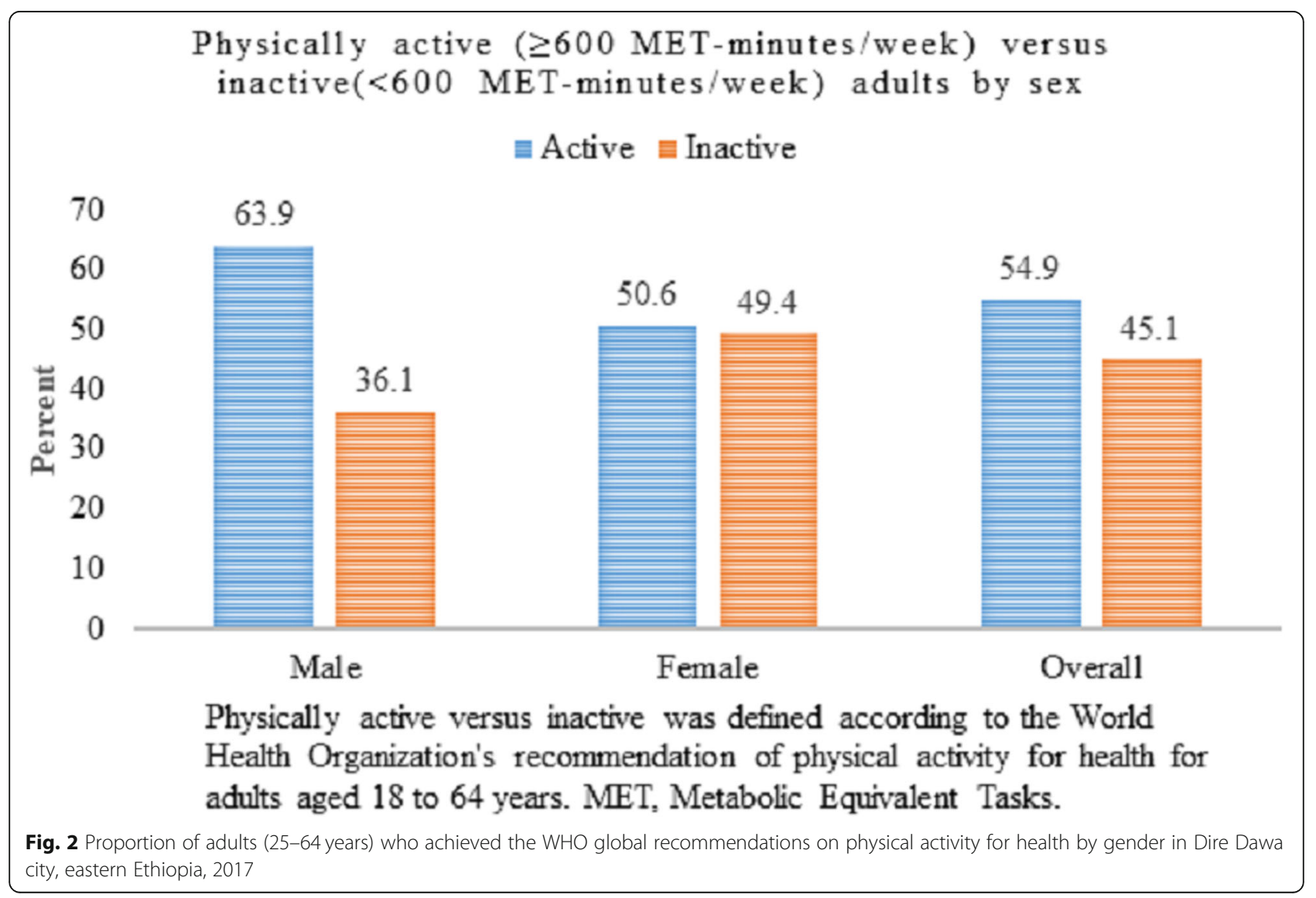


Table 3 Distribution of adults (25-64 years) who achieved and did not achieve the World Health Organization (WHO) recommendations on physical activity for health in Dire Dawa city, eastern Ethiopia, 2017

\begin{tabular}{|c|c|c|c|}
\hline \multirow[t]{2}{*}{ Variables } & \multirow{2}{*}{$\begin{array}{l}\text { All groups, } \\
n=872\end{array}$} & \multicolumn{2}{|c|}{ Proportion of adults by the $\mathrm{WHO}$ global recommendations on physical activity for health } \\
\hline & & $\begin{array}{l}\text { Achieved the recommended level, } \\
n=479 ; \%(n)\end{array}$ & $\begin{array}{l}\text { Did not achieve the recommended level, } \\
n=393 ; \%(n)\end{array}$ \\
\hline \multicolumn{4}{|l|}{ Age } \\
\hline $25-29$ & 231 & $28.0(134)$ & $24.7(97)$ \\
\hline $30-34$ & 326 & $38.4(184)$ & $36.1(142)$ \\
\hline $45-54$ & 124 & $13.6(65)$ & $15.0(59)$ \\
\hline $55-64$ & 191 & $20.0(96)$ & $24.2(95)$ \\
\hline \multicolumn{4}{|l|}{ Sex } \\
\hline Male & 285 & $38.0(182)$ & $26.2(103)$ \\
\hline Female & 587 & $62.0(297)$ & $73.8(290)$ \\
\hline \multicolumn{4}{|l|}{ Education } \\
\hline No formal education & 125 & $11.9(57)$ & $17.3(68)$ \\
\hline Primary education & 327 & $40.1(192)$ & $34.4(135)$ \\
\hline Secondary education & 316 & $35.7(171)$ & $36.9(145)$ \\
\hline College and above & 104 & $12.3(59)$ & $11.5(45)$ \\
\hline \multicolumn{4}{|l|}{ Marital status } \\
\hline Married & 582 & $65.8(315)$ & $67.9(267)$ \\
\hline Not married & 173 & $21.9(105)$ & $17.3(68)$ \\
\hline Divorced/widowed & 117 & $12.3(59)$ & $14.8(58)$ \\
\hline \multicolumn{4}{|l|}{ Occupation } \\
\hline Office employee & 234 & $31.1(149)$ & $21.6(85)$ \\
\hline Merchant & 134 & $15.7(75)$ & $15.0(59)$ \\
\hline Unemployed & 396 & $39.5(189)$ & $52.7(207)$ \\
\hline Other $^{b}$ & 108 & $13.8(66)$ & $10.7(42)$ \\
\hline \multicolumn{4}{|l|}{ Ethnicity } \\
\hline Oromo & 302 & $35.1(168)$ & $34.0(134)$ \\
\hline Amhara & 428 & $47.4(227)$ & $51.2(201)$ \\
\hline Others $^{a}$ & 142 & $17.5(84)$ & $14.8(58)$ \\
\hline \multicolumn{4}{|l|}{ Body mass index } \\
\hline Underweight $\left(<18.5 \mathrm{Kg} / \mathrm{m}^{2}\right)$ & 66 & $7.9(38)$ & $7.1(28)$ \\
\hline Normal $\left(18.5-24.99 \mathrm{Kg} / \mathrm{m}^{2}\right)$ & 472 & $57.0(273)$ & $50.6(199)$ \\
\hline Overweight $\left(\geq 25.0 \mathrm{Kg} / \mathrm{m}^{2}\right.$ ) & 334 & 35.1 (168) & $42.2(166)$ \\
\hline
\end{tabular}

${ }^{a}$ Ethio-Somali, Harari, Guraghe, Tigraway, Wolayta, Silte, Afar

bhousewife, pensioner, janitor, daily laborer

cAdults, 18-64 years, should accumulate at least 600 MET-minutes of physical activity per week (2); WHO, World Health Organization

$52.7 \%$ of the same group did not. In contrast, a positive difference between the proportion of physically active and physically inactive adults are observed among men, among those who had primary education, office employees, and among those who had a normal BMI (Table 3).

\section{Factors associated with physical activity status}

In the bivariate binary logistic regression being male, primary education attendance and those who had a normal BMI had a positive and significant association with being physically active.
In contrast, unemployed adults were less likely to be physically active. Compared to the office employed adults, unemployed adults were $48 \%$ less likely to be physically active (Table 4 ).

In the multivariable binary logistic regression, however, the positive association of adults who had normal BMI and those who had a primary school attendance with achieving physical activity of 600 MET-minutes per week or more was no longer significant. On the other hand, unemployment status and being male remained statistically significant. Adult males were $45 \%$ more likely to be 
Table 4 Factors associated with doing physical activity of 600 MET-minutes per week or more among adults (25-64 years) in Dire Dawa city, eastern Ethiopia, 2017

\begin{tabular}{|c|c|c|c|c|}
\hline Variables & cOR, $(95 \% \mathrm{Cl})$ & $p$-value & $\mathrm{aOR},(95 \% \mathrm{Cl})$ & $p$-value \\
\hline \multicolumn{5}{|l|}{ Age } \\
\hline $55-64$ & Ref. & & Ref. & \\
\hline $25-29$ & $1.34(0.91,1.98)$ & 0.134 & $1.33(0.84,2.10)$ & 0.228 \\
\hline $30-44$ & $1.27(0.89,1.82)$ & 0.187 & $1.22(0.81,1.82)$ & 0.342 \\
\hline $45-54$ & $1.10(0.70,1.74)$ & 0.675 & $1.08(0.66,1.74)$ & 0.766 \\
\hline \multicolumn{5}{|l|}{ Sex } \\
\hline Female & Ref. & & Ref. & \\
\hline Male & $1.73(1.29,2.31)$ & $<0.001$ & $1.45(1.05,1.99)$ & 0.024 \\
\hline \multicolumn{5}{|l|}{ Education } \\
\hline No formal education & Ref. & & Ref. & \\
\hline College diploma and above & $1.52(0.89,2.60)$ & 0.126 & $0.72(0.38,1.36)$ & 0.308 \\
\hline Secondary (9-12 grade) & $1.40(0.91,2.14)$ & 0.125 & $0.88(0.53,1.46)$ & 0.630 \\
\hline Primary (1-8 grade) & $1.72(1.12,2.64)$ & 0.012 & $1.35(0.85,2.15)$ & 0.206 \\
\hline \multicolumn{5}{|l|}{ Marital status } \\
\hline Married & Ref. & & Ref. & \\
\hline Never married & $2.31(0.93,1.85)$ & 0.127 & $1.26(0.86,1.86)$ & 0.237 \\
\hline Divorced/widowed & $0.86(0.58,1.28)$ & 0.465 & $0.92(0.61,1.40)$ & 0.704 \\
\hline \multicolumn{5}{|l|}{ Occupation } \\
\hline Employed office work & Ref. & & Ref. & \\
\hline Merchant & $0.73(0.47,1.12)$ & 0.662 & $0.67(0.42,1.06)$ & 0.087 \\
\hline Unemployed & $0.52(0.37,0.73)$ & $<0.001$ & $0.51(0.35,0.75)$ & 0.001 \\
\hline Other ${ }^{b}$ & $0.90(0.56,1.43)$ & 0.648 & & \\
\hline \multicolumn{5}{|l|}{ Ethnicity } \\
\hline Oromo & Ref. & & & \\
\hline Amhara & $0.87(0.64,1.19)$ & 0.384 & & \\
\hline Other $^{\mathrm{a}}$ & $1.15(0.76,1.73)$ & 0.513 & & \\
\hline \multicolumn{5}{|l|}{ BMl } \\
\hline$>=25.0 \mathrm{~kg} / \mathrm{m}^{2}$ & Ref. & & Ref. & \\
\hline$<18.5 \mathrm{~kg} / \mathrm{m}^{2}$ & $1.39(0.81,2.38)$ & 0.227 & $1.47(0.85,2.56)$ & 0.170 \\
\hline $18.5-24.99 \mathrm{~kg} / \mathrm{m}^{2}$ & $1.35(1.02,1.80)$ & 0.039 & $1.25(0.93,1.68)$ & 0.142 \\
\hline
\end{tabular}

'Ethio-Somali, Harari, Guraghe,Tigraway Wolayta, Silte, Afar

b housewife, pensioner, janitor, daily laborer; cOR, crude odds ratio; aOR, adjusted odds ration; Cl, confidence interval

physically active compared to women. Compared to office employed adults, those who were unemployed had an inverse association of doing the recommended level of physical activity for health (Table 4).

\section{Discussion}

The proportion of physically active adults in this study was $54.9 \%$. This study also found that unemployment status had a negative association with being physically active. In contrast, male gender had a positive association with being physically active.

Several multi-country studies that used the GPAQ to assess physical activity reported that level of physical inactivity, performing less than 600 MET-minutes per week [2], greatly varies from country to country, and also at the sub-national level [6, 25]. For example, Guthold et al. reported the proportion of physically active adults in 22 African countries, with the lowest value being in Mali (46.8\%) and the highest in Mozambique (95.6\%) [6]. A systematic review by Shahara et al. reported the proportion of physical inactivity ranging from $20.1 \%$ in Comoros to $67.6 \%$ in Saudi Arabia, and also in three subnational samples, the proportion ranged from $40.7 \%$ in Algeria to $51.3 \%$ in Mauritania, and $86.8 \%$ in Sudan [25]. The proportion of physically inactive adults in the current study setting 
was $45.1 \%$, which is higher compared to the study from Mozambique or Comoros, but it is lower compared to other studies in Mali, Sudan, Mauritania, and Saudi Arabia [6, 25]. However, it is worth to note that our study was conducted at a sub-national level, and hence the level of physical inactivity may seem higher compared to studies that reported estimates at the national level $[6,13,25]$.

In this study, physical inactivity was two times higher compared to that of the 2015 national STEPS survey specifically reported for Dire Dawa, 19.7\% [7]. Two reasons could explain the observed difference: Firstly, the 2015 national STEPS survey included both urban and rural population of the DDAC, and this mix of a relatively physically active rural population as noted in other studies $[13,14]$ in the estimation might have masked the true level of physical inactivity in the urban Dire Dawa. Secondly, disproportionately more women were included in our study, and this may have inflated the level of physical inactivity as research evidence consistently reported women to be physically inactive than men $[11,13,14]$. Furthermore, the climate of Dire Dawa is hot [18], and this may have contributed to the high-level physical inactivity as different studies reported the influence of the built environment on physical activity [26]. Four out of every ten persons were physically inactive in the present study. This finding suggests the need to promote physical activity, which in turn requires a multi-sectoral, and multi-disciplinary public health response $[1,27]$. With a highlevel of physical inactivity, there is an increased risk of poor health outcome as several studies reported that physical inactivity is causally associated with deaths from non-communicable diseases and all-cause mortality $[9,10,28,29]$.

In the study setting, as in other low-and-middle-income countries (LMICs) $[6,13,30]$, physical activity at workplaces and during transport contributed a significant share to the total physical activity. Due to a very low motor vehicle ownership, 8 motor vehicles per 1000 people in Ethiopia [31], most people walk to get to and from places. We also hypothesize that, in the study setting, people engage in activities that are labor-intensive during household chores or at workplaces due to low availability and access to technological devices that help them to get their work done with a low energy expedition. However, with a growth in the economy coupled with rapid urbanization, the current level of domain-specific contributions of physical activity at workplaces, and during transport in the study setting is expected to decrease as noted elsewhere [32, 33]. Therefore, to sustainably improve population-level physical activity and contribute towards reducing the global physical inactivity by $10 \%$ by 2025 [34], emphasis should be given to a systems approach that focuses on populations and the complex interactions among the correlates of physical inactivity including environmental factors [1, 27, 35, 36].

The contribution of leisure-time physical activity to the total physical activity in the present study was very low as in other similar settings [14, 30]. For example, in a study in Mozambique, Padrao et al. reported that leisure-time physical activity by women of age 35 to 44 years constituted only $2.2 \%$ of the total physical activity and $18.9 \%$ by men of age $25-34$ years [14]. Even though there was a significant difference between men and women regarding the average contribution of leisuretime physical activity to the total physical activity in the study setting, it was very low compared to the study reported in Mozambique. Research evidence indicated that individuals from a higher socioeconomic status were likely to be contributing to a higher level of leisure-time physical activity [37]. However, no difference was reported in the physical activity domains other than the leisure-time physical activity domain [37].

For additional health benefits, research evidence suggests that adults should increase the intensity of physical activity well beyond the minimum recommended level, 600 MET-minutes per week [10, 29]. For example, compared to no physical activity, adult's activity level of 600 MET-minutes per week lowers the risk of diabetes by $2 \%$, and an increase of this level to 3600 MET-minutes per week reduces the risk by an additional 19\% [29]. In our study setting, only $37.0 \%$ of the adults did a high-level total physical activity, and it was significantly different between men and women: $47.6 \%$ for men versus $31.9 \%$ for women. This finding is very low compared to a study reported $83.2 \%$ for urban women and $78.9 \%$ for urban men in Mozambique [14], but higher compared to the study in Bangladesh, 19.5\% [13]. In addition to lowering the risk to non-communicable diseases, high-level physical activity was also reported to eliminate the risk of mortality associated with sitting time [28]. In the present study, due to 4-h or more sitting time coupled with a lower proportion of high-level physical activity, a significant risk of poor health outcome remains a challenge. For example, a meta-analysis reported a $27 \%$ increased risk of mortality among adults who sat less than 4-h per day and were in the lowest activity quintile [28].

In this study, we found that unemployment and male gender were significantly associated with physical activity. Consistent with previous reports [2, 16, 38, 39], unemployed adults were less likely to perform the recommended level of physical activity for health. We hypothesize that unemployed adults were likely to be in low socioeconomic status, and have poor access to resources for participation in physical activity [40]. A study on physical activity among Nepalese adults, however, reported that self- or government-employed adults were 
physically inactive [30]. As reported in previous studies, male adults were physically active compared to women [12, 30, 38, 41]. However, consistent individual-level correlates of physical activity in previous studies including age and level of education [14,30] were not significantly associated with physical activity in our study. This may be due to a relative influence of the built environment over the individual factors in the study setting such as the hot climate as noted elsewhere $[25,26]$. However, an explanation for this needs further investigation to assess contextual factors in greater depth.

The strengths of this study include that we used the GPAQ, and followed the GPAQ analysis protocol [22], which we believe allows comparison of findings from different settings. As an aid for consistency of physical activity measurement, we used the GPAQ showcards [22] and reported findings on all the three domain-specific physical activity (work, during transport to and from places, and leisure). However, this study is not without limitation, and hence worth to mention to help readers interpret the findings with caution. Firstly, the study unintentionally included more women, and this might have biased the overall estimate of physical activity in the study setting. Secondly, we did not assess the social, cultural, and environmental factors that may influence physical activity, and the authors would like to suggest that future studies consider the effect of these factors on physical activity. Finally, the cross-sectional nature of our study did not allow us to see the temporal relation between the assessed factors and physical activity.

\section{Conclusion}

This study presented findings on the most overlooked public health problem in a resource-poor setting [11], yet a global pandemic that drives the burden of noncommunicable diseases and premature mortality [11]. In the study setting, $54.9 \%$ of urban adults were physically active, and women were less active than men. Workplace physical activity and activity during transport contributed a significant share to the total weekly physical activity. To further improve the proportion of physically active people in the study setting, promoting physical activity at workplaces, improving trails for commuting, and targeted expansion of facilities that satisfy the needs of unemployed adults and women will be beneficial.

\section{Additional file}

Additional file 1: Table S1. The Global Physical Activity Questionnaire (GPAQ). The GPAQ measures sedentary behavior and three physical activity domains: work, travel to and from places, and recreational activities. (DOCX 17 kb)

\section{Abbreviations}

aOR: Adjusted Odds Ratio; Cl: Confidence Interval; cOR: Crude Odds Ratio; DALY: Disability Adjusted Life Years; DDAC: Dire Dawa Administrative Council; GPAQ: Global Physical Activity Questionnaire; IHRERC: Institutional Health Research Ethics Review Committee; IQR: Inter Quartile Range; LMICs: Low-and Middle-Income Countries; MCAR: Missing completely at random; MET: Metabolic Equivalent Tasks; MICE: Multiple Imputation by Chained Eqs.; NCD: Non-Communicable Diseases; PAF: Population Attributable Fraction; STEPS: WHO STEPwise approach to Surveillance; WHO: World Health Organization

\section{Acknowledgements}

The authors thank the study participants and research assistants involved in this study. We are also grateful to Haramaya University for providing us with the 2015 staff research grant award for the metabolic syndrome study.

\section{Author's contributions}

Conceived and designed the study: $\mathrm{MM}, \mathrm{BH}, \mathrm{HS}$ and $\mathrm{AB}$; Adopting instrument and acquisition of data: $\mathrm{MM}, \mathrm{BH}$, and HS; Data management: MM, $\mathrm{BH}$, and HS. Analyzed the data and interpreted findings: MM; Drafting the manuscript: $M M$; Critical revision and approval of the final manuscript: MM, $\mathrm{BH}, \mathrm{HS}$, and $\mathrm{AB}$.

\section{Funding}

This study was part of a bigger study that received the 2015 Haramaya University annual staff research grant. The funder has no role in the design of the study, data collection, analysis, interpretation of the data, and in writing the manuscript.

\section{Availability of data and materials}

All data pertaining to the findings are presented in this paper. However, the data can be obtained from the corresponding author any time on reasonable request.

\section{Ethics approval and consent to participate}

The Institutional Health Research Ethics Review Committee (IHRERC) of Haramaya University College of Health and Medical Sciences approved the study. Informed written consent was obtained from all included participants before data collection, and no personal identifying information was collected.

\section{Consent for publication}

Not applicable.

\section{Competing interests}

The authors declare that they have no competing interest.

\section{Author details}

'Department of Epidemiology and Biostatistics, College of Health and Medical Sciences, School of Public Health, Haramaya University, P.O. Box 235, Harar, Ethiopia. ${ }^{2}$ Department of Public Health and Health Policy, College of Health and Medical Sciences, School of Public Health, Haramaya University, Harar, Ethiopia. ${ }^{3}$ Department of Environmental Health Sciences, College of Health and Medical Sciences, Haramaya University, Harar, Ethiopia. ${ }^{4}$ Research Centre for Generational Health and Ageing, School of Medicine and Public Health, Faculty of Health and Medicine, University of Newcastle, Newcastle, Australia.

Received: 26 November 2018 Accepted: 11 August 2019 Published online: 22 August 2019

\section{References}

1. Kohl HW, Craig CL, Lambert EV, Inoue S, Alkandari JR, Leetongin G, et al. The pandemic of physical inactivity: global action for public health. Lancet. 2012;380:12

2. WHO. Global recommendation on physical ctivity for health: World Health Organization; 2010 [Available from: http://www.who.int/dietphysicalactivity/ factsheet_recommendations/en/.

3. Lee I, Shiroma EJ, Lobelo F, Puska P, Blair SN, Katzmarzyk PT. Effect of physical inactivity on major non-communicable diseases worldwide: 
an analysis of burden of disease and life expectancy. Lancet. 2012:380:11.

4. Ding D, Lawson KD, Kolbe-Alexander TL, Finkelstein EA, Katzmarzyk PT, Mechelen W, et al. The economic burden of physical inactivity: a global analysis of major non-communicable diseases. Lancet. 2016;388:14.

5. Sallis JF, Bull F, Guthold R, Heath GW, Inoue S, Kelly P, et al. Progress in physical activity over the Olympic quadrennium. Lancet. 2016:12.

6. Guthold R, Louazani SA, Riley LM, Cowan MJ, Bovet P, Damasceno A, et al. Physical activity in 22 African countries: results from the World Health Organization STEPwise approach to chronic disease risk factor surveillance. AmJ Prev Med. 2011;41(1):9.

7. EPHI. Ethiopia STEPS report on risk factors for non-communicable diseaes and prevalence of selected NCDs. Addis Ababa: Ethiopian Public Health Institute; 2016.

8. WHO. Fact sheet: Ethiopia (Addis Ababa) STEPS Survey 2006 [Available from: www.who.int/ncds/surveillance/steps/2006_Ethiopia_FactSheet_EN.pdf.

9. Huerta JM, Chirlaque MD, Tormo MJ, Buckland G, Ardanaz E, Arriola L, et al. Work, household, and leisure-time physical activity and risk ofmortality in the EPIC-Spain cohort. Prev Med. 2016;85(2016):7.

10. Samitz G, Egger M, Zwahlen M. Domains of physical activity and all-cause mortality: systematic review and dose-response meta-analysis of cohort studies. Int J Epidemiol. 2011;40:19.

11. Bauman AE, Reis RS, Sallis JF, Wells JC, Loos RF, Martin BW. Correlates of physical activity: why are some people physically active and others not? Lancet. 2012;380:14

12. Thanamee S, Pinyopornpanish K, Wattanapisit A, Suerungruang S, Thaikla K, Jiraporncharoen W, et al. A population-based survey on physical inactivity and leisure time physical activity among adults in Chiang Mai, Thailand, 2014. Archives of Public Health. 2017;75(41):9.

13. Moniruzzaman M, Zaman MM, Islalm MS, Ahasan HA, Kabir H, Yasmin R. Physical activity levels in Bangladeshi adults: results from STEPS survey 2010. Public Health. 2016.

14. Padrão P, Damasceno A, Silva-Matos C, Prista A, Lunet N. Physical activity patterns in Mozambique: urban/rural differences during epidemiological transition. Prev Med. 2012;55:6.

15. Saelens BE, Handy SL. Built environment correlates of walking: a review. Med Sci Sports Exerc. 40(7 Suppl):17.

16. Newtonraj A, Velavan A, Singh Z, Chauhan RC, Murugan N, Mani M. Factors associated with physical inactivity among adult urban population of Puducherry, India: a population based cross-sectional study. J Clin Diagn Res. 2017;11(5):3

17. World population review. Population of cities in Ethiopia (2018) [Available from: http://worldpopulationreview.com/countries/ethiopia-population/cities/.

18. Dire Dawa City Adminstration-Ethiopia. [Available from: http://www.ethiopia. gov.et/dire-dawa-city-administration.

19. Dean AG, Sullivan KM, Soe MM. OpenEpi: open source epidemiologic statistics for public health. Atlanta, USA: Emory University; 2009.

20. Workalemahu T, Gelaye B, Berhane Y, Williams MA. Physical activity and metabolic syndrome among Ethiopian adults. Am J Hypertens. 2013;26(4):535-40.

21. WHO. WHO STEPS instrument (core and expanded): WHO STEPwise approach to chronic disease risk factor surveillance- Instrument v2.1 [Available at: www.who.int/ncds/surveillance/steps/STEPS_Instrument_v2.1.pdf].

22. WHO. GPAQ: global physical activity questionnaire (version 2.0). Department of Chronic Diseases and Health Promotion, WHO 2010. [Available from: http://www.who.int/chp/steps/resources/GPAQ_Analysis_Guide.pdf.

23. WHO. The WHO STEPwise approach to noncommunicable disease risk factor surveillance: WHO STEPS surveillance manual. WHO, 2017. [Available at: https://www.who.int/ncds/surveillance/steps/manual/en/].

24. Azur MJ, Stuart EA, Frangakis C, Leaf PJ. Multiple imputation by chained equations: what is it and how does it work? Int J Methods Psychiatr Res. 2011;20(1):10

25. Sharara E, Akik C, Ghattas H, Obermeyer CM. Physical inactivity, gender and culture in Arab countries: a systematic assessment of the literature. BMC Public Health. 2018;18:19.

26. Bosdriesz JR, Witvliet MI, Visscher TLS, Kunst AE. The influence of the macroenvironment on physical activity: a multilevel analysis of 38 countries worldwide. Int J Behav Nutr Phys Act. 2012;9:13.

27. Reis RS, Salvo D, Ogilvie D, Lambert EV, Goenka S, Brownson RC. Scaling up physical activity interventions worldwide: stepping up to larger and smarter approaches to get people moving. Lancet. 2016:12.
28. Ekelund UIf S-JJ, Brown WJ, Fagerland MW, Owen N, Powell KE, et al. Does physical activity attenuate, or even eliminate, the detrimental association of sitting time with mortality? A harmonised meta-analysis of data from more than 1 million men and women. Lancet. 2016:388:9.

29. Kyu HH, Bachman VF, Alexander LT, Mumford JE, Afshin A, Estep K, et al. Physical activity and risk of breast cancer, colon cancer, diabetes, ischemic heart disease, and ischemic stroke events: systematic review and dose-response meta-analysis for the global burden of disease study 2013. BMJ. 2016;354:10.

30. Vaidya A, Krettek A. Physical activity level and its sociodemographic correlates in a peri-urban Nepalese population: a cross-sectional study from the Jhaukhel-Duwakot health demographic surveillance site. Int J Behav Nutr Phys Act. 2014;11:12.

31. List of countries by vehicles per capita: Wikipedia; 2017 [updated September 2018; cited 2018 September 13]. Available from: https:/en. wikipedia.org/wiki/List_of_countries_by vehicles_per_capita.

32. Allen L, Williams J, Townsend N, Mikkelsen B, Roberts N, Foster C, et al. Socioeconomic status and non-communicable disease behavioural risk factors in low-income and lower-middle-income countries: a systematic review. Lancet Glob Health. 2017;5:13.

33. Attard SM, Howard A, Herring AH, Zhang B, Du S, Aiello AE, et al. Differential associations of urbanicity and income with physical activity in adults in urbanizing China: findings from the population-based China health and nutrition survey 1991-2009. Int J Behav Nutr Phys Act. 2015;12.

34. WHO. Global action plan on physical activtiy 2018-2030: more active people for a healthier world: WHO; 2018 [Available at: www.who.int/letsbe-active/en/\#Beactive].

35. de Nazelle A, Nieuwenhuiijsen MJ, Antó JM, Brauer M, Briggs D, BraunFahrlander $C$, et al. Improving health through policies that promote active travel: a review of evidence to support integrated health impact assessment. Environ Int. 2011;37:12.

36. Jongeneel-Grimen B, Droomers M, van Oers HAM, Stronks K, Kunst AE. The relationship between physical activity and the living environment: a multilevel analyses focusing on changes over time in environmental factors. Health Place. 2014;26:12.

37. Stalsberg R, Pedersen AV. Are differences in physical activity across socioeconomic groups associated with choice of physical activity variables to report? Int J Environ Res Public Health. 2018:15(5).

38. Ying CY, Kuay LK, Huey TC, Hock LK, Abd Hamid HA, Omar MA, et al. Prevalence and factors associated with physical inactivity among Malaysian adults. Southeast Asian J Trop Med Public Health. 2014;45:2.

39. Koyanagi A, Stubbs B, Smith L, Gardner B, Vancampfort D. Correlates of physical activity among community-dwelling adults aged 50 or over in six low- and middle-income countries. PLoS One. 2017;12(10):e0186992.

40. Estabrooks PA, Lee RE, Gyurcsik NC, et al. Resources for physical activity participation: does availability and accessibility differ by neighborhood socioeconomic status? Ann Behav Med. 2003;25(2):5.

41. Baldew SSM, Krishnadath ISK, Smits CCF, Toelsie JR, Vanhees L, Cornelissen V. Self-reported physical activity behavior of a multi-ethnic adult population within the urban and rural setting in Suriname. BMC Public Health. 2015;15.

\section{Publisher's Note}

Springer Nature remains neutral with regard to jurisdictional claims in published maps and institutional affiliations.

Ready to submit your research? Choose BMC and benefit from:

- fast, convenient online submission

- thorough peer review by experienced researchers in your field

- rapid publication on acceptance

- support for research data, including large and complex data types

- gold Open Access which fosters wider collaboration and increased citations

- maximum visibility for your research: over $100 \mathrm{M}$ website views per year

At $\mathrm{BMC}$, research is always in progress.

Learn more biomedcentral.com/submissions 